\title{
Efficacy and harms of convalescent plasma for treatment of hospitalized COVID-19 patients: a systematic review and meta-analysis
}

\author{
Alejandro Piscoya ${ }^{1,2}$, Luis F. Ng-Sueng ${ }^{1,3}$, Angela Parra del Riego ${ }^{4}$, Renato Cerna-Viacava ${ }^{4}$, \\ Vinay Pasupuleti ${ }^{5}$, Priyaleela Thota ${ }^{6}$, Yuani M. Roman ${ }^{7}$, Adrian V. Hernandez ${ }^{7}$
}

\author{
${ }^{1}$ Unidad de Revisiones Sistemáticas y Meta-análisis, Guías de Práctica Clínica y \\ Evaluaciones de Tecnologías Sanitarias (URSIGET), Universidad San Ignacio de \\ Loyola, Lima, Peru \\ ${ }^{2}$ Hospital Guillermo Kaelin de la Fuente, Lima, Peru \\ ${ }^{3}$ Department of Internal Medicine, Henry Ford Hospital, Detroit, MI, United States \\ ${ }^{4}$ Universidad Peruana de Ciencias Aplicadas, Lima, Peru \\ ${ }^{5}$ MedErgy Health Group Inc., Yardley, PA, United States \\ ${ }^{6}$ Hemex Health Inc., Portland, OR, United States \\ ${ }^{7}$ University of Connecticut School of Pharmacy, Storrs, CT, United States
}

Submitted: 24 October 2020; Accepted: 17 January 2021

Online publication: 18 February 2021

Arch Med Sci 2021; 17 (5): 1251-1261

DOI: https://doi.org/10.5114/aoms/132492

Copyright (c) 2021 Termedia \& Banach

\section{Abstract}

Introduction: We systematically reviewed benefits and harms of convalescent plasma (CP) in hospitalized COVID-19 patients.

Material and methods: Randomized controlled trials (RCTs) and observational studies assessing CP effects on hospitalized, adult COVID-19 patients were searched until November 24, 2020. We assessed risk of bias (RoB) using Cochrane RoB 2.0 and ROBINS-I tools. Inverse variance random effect meta-analyses were performed. Quality of evidence was evaluated using GRADE methodology. Primary outcomes were all-cause mortality, clinical improvement, and adverse events.

Results: Five RCTs $(n=1067)$ and 6 cohorts $(n=881)$ were included. Three and 1 RCTs had some concerns and high RoB, respectively; and there was serious RoB in all cohorts. Convalescent plasma did not reduce all-cause mortality in RCTs of severe ( $R R=0.60,95 \% \mathrm{Cl}: 0.33-1.10)$ or moderate ( $R R=0.60,95 \% \mathrm{Cl}: 0.09-3.86$ ) COVID-19 vs. standard of care (SOC); CP reduced all-cause mortality vs. SOC in cohorts ( $R R=0.66,95 \% \mathrm{Cl}: 0.49-0.91$ ). Convalescent plasma did not reduce invasive ventilation vs. SOC in moderate disease ( $R R=0.85,95 \% \mathrm{Cl}: 0.47-1.55)$. In comparison to placebo + SOC, $C P$ did not affect all-cause mortality $(R R=0.75$, $95 \% \mathrm{Cl}: 0.48-1.16)$ or clinical improvement $(\mathrm{HR}=1.07,95 \% \mathrm{Cl}: 0.82-1.40)$ in severe patients. Adverse and serious adverse events were scarce, similar between CP and controls. Quality of evidence was low or very low for most outcomes.

Conclusions: In comparison to SOC or placebo + SOC, CP did not reduce allcause mortality in RCTs of hospitalized COVID-19 patients. Convalescent plasma did not have an effect on other clinical or safety outcomes. Until now there is no good quality evidence to recommend CP for hospitalized COVID-19 patients.

Key words: convalescent plasma, coronavirus, all-cause mortality.

\section{Introduction}

The recent outbreak of coronavirus disease 19 (COVID-19), an infection caused by the virus SARS-CoV-2, in Wuhan, China, has caused devas-
Corresponding author: Prof. Adrian V. Hernandez University of Connecticut School of Pharmacy Storrs, CT

United States E-mail: adrian.hernandezdiaz@uconn.edu 
tating repercussions worldwide [1-3]. The epidemic spread rapidly, and on March 11, 2020 it was characterized as a pandemic by the World Health Organization (WHO). Until August $23^{\text {rd }} 2020$, there have been 23546173 cases, and 811436 deaths worldwide [4]. In the attempt to stop this pandemic, especially in severe cases, there have been several interventions evaluated in randomized controlled trials for the treatment of COVID-19 $[2,4,5]$.

Convalescent plasma (CP) therapy is a classic and old immunotherapy, whose main determinant of efficacy is its neutralizing activity. It also is supposed to have antiviral activity based on the large reductions of the viral loads in a case series [6]. According to a case series of 13 patients with Middle East respiratory syndrome coronavirus (MERS-CoV), for an effective infusion of $C P$, donor plasma should have at least the neutralization activity of a plaque-reduction neutralization test (PRNT) titer of $1: 80$ [7].

There are several studies, most of them observational and a few randomized controlled trials (RCTs), evaluating CP efficacy and safety in several infectious outbreaks. Unfortunately, there are still no good quality systematic reviews and metaanalyses of RCTs in COVID-19 patients. In a case series of 80 patients with severe acute respiratory syndrome coronavirus (SARS-CoV) in 2003, the authors reported a higher 22-day hospital discharge rate in those 42 patients who received $C P$ within the first 14 days of disease vs. those 38 patients who received CP after 14 days of disease $(58.3 \%$ vs. $15.6 \%)$, and a reduction in the mortality rate (6.3\% vs. $21.9 \%)$, with no adverse events reported [8]. In a matched controlled prospective cohort among 93 patients with severe pandemic influenza A (H1N1) 2009 virus infection, the CP group had a reduced mortality rate in comparison to those not receiving $\mathrm{CP}(\mathrm{OR}=0.20,95 \% \mathrm{Cl}$ : 0.06-0.69) [9]. However, adverse events such as transfusionrelated acute lung injury (TRALI) and transfusionrelated circulation overload (TACO) raise concern since data are scarce [10].

On August 23 $3^{\text {rd }} 2020$, the US Food and Drug Administration (FDA) issued an Emergency Use Authorization (EUA) for the use of CP as a treatment of COVID-19 in hospitalized patients [11]. This decision was based on results of a recent case series study that claimed that 7-day mortality was reduced by $35 \%$ in relative terms in 515 recipients of high IgG CP in comparison to 561 recipients of low IgG CP (7-day mortality: $8.9 \%$ vs. $13.7 \%$, respectively) [12]. On September $1^{\text {st }} 2020$, the COVID-19 Treatment Guidelines Panel stated there were insufficient data to recommend either for or against the use of CP and it should not be considered standard of care [13].
In the need of more evidence-based practice guidelines for the treatment of severe COVID-19, the aim of this systematic review and metaanalysis was to evaluate the efficacy and safety of CP in human studies for the treatment of severely ill COVID-19 patients.

\section{Material and methods}

\section{Search strategy and selection criteria}

We performed a systematic review of RCTs and observational studies evaluating the effects of CP in hospitalized, confirmed COVID-19, adult patients. We included RCTs, case series, and cohorts. We excluded studies with patients $<18$ years old, pregnant patients, and hepatitis B or HIV coinfection, narrative reviews, editorials, and letters to the editor.

Searches were conducted until November 24, 2020 in 5 engines: PubMed, Web of Science, Scopus, Embase and the Cochrane Library; pre-prints on medRxiv.org, and ongoing RCTs on: www.ClinicalTrials.gov, www.who.int/ictrp/about/en/, and www. clinicaltrialsregister.eu/. Search strategies were adjusted for each engine using the following combination of keywords: "convalescent plasma" AND ("COVID-19" OR "coronavirus" OR "coronavirus disease" OR "coronavirus disease-19" OR "severe acute respiratory syndrome" OR "SARS-CoV-2") with no limitations for time or language. Included studies specified at least one efficacy or harm outcome. PubMed strategy is included in the Supplementary material (Supplementary Appendix S1).

Three reviewers (VP, AP, LNS) collected records in www.myendnoteweb.com. Two independent reviewers (APdR, RCV) assessed titles and abstracts for eligibility according to the inclusion and exclusion criteria. Discrepancies were resolved by discussion. Three independent reviewers (LNS, APdR, RCV) assessed full-text articles and extracted data with disagreements resolved by a third reviewer (AP). Extracted information included: study authors, year of publication, study design, number of patients, country, median age, proportion of males, comorbidities (obesity, hypertension, diabetes, coronary artery disease (CAD), chronic kidney disease (CKD), chronic obstructive pulmonary disease (COPD)), PCR method for COVID-19 diagnosis, CP dose and duration, concomitant treatments for both arms, primary outcomes per arm, and secondary outcomes per arm.

Primary outcomes were all-cause mortality, and clinical improvement or recovery (e.g. 2-point reduction in a 6-point ordinal severity scale or other definitions). Secondary outcomes were overall and specific adverse events, serious adverse events (SAEs), need for invasive ventilation, length of hospital stay, and treatment discontinuation. 


\section{Data analysis}

Assessment of risk of bias was performed independently by 3 investigators (AP, APdR, RCV) using the Cochrane RoB 2.0 tool [14] for RCTs, and the ROBINS-I tool [15] for cohort studies with a third reviewer $(\mathrm{AVH})$ resolving discrepancies when needed.

We reported our systematic review according to 2009 PRISMA guidelines [16]. Effects of CP on outcomes from individual studies were reported as hazard ratio (HR) or absolute risk difference (ARD) or relative risk (RR) and their 95 confidence intervals (95\% Cls) for dichotomous outcomes and mean differences (MD) and their $95 \% \mathrm{Cls}$ for continuous outcomes. Inverse variance random effect meta-analyses were performed when outcome data were available for at least 2 studies judged to be homogeneous about study characteristics. Between study variance $\tau^{2}$ was calculated with the Paule-Mandel method. Effects from meta-analyses were reported as relative risks (RR) and their $95 \% \mathrm{Cls}$, and heterogeneity of effects among studies was quantified with the $R^{2}$ statistic (an $R^{2}>60 \%$ means high heterogeneity of effects). We primarily stratified analyses by study design (i.e. RCTs and cohort studies separately). R 3.5.1 (www.r-project. org) was used for meta-analyses.

The quality or certainty of evidence was evaluated using the GRADE methodology, which covers 5 items: risk of bias, inconsistency, indirectness, imprecision, and publication bias [17]. Quality of evidence was evaluated per specific comparison and per outcome, and described in summary of findings (SoF) tables; GRADEpro GDT was used to create SoF tables [18].

This was a systematic review of published studies, and no patients were involved in setting the research question or the outcome measures; thus, no ethics approval was required.

\section{Results}

We identified 1533 studies with our search strategy. After removing duplicates, 1103 studies were screened for eligibility by reviewing titles and abstracts. Among these, 1077 were excluded and 27 full-text articles were further assessed for eligibility. No further exclusion of full-text articles was done. Five RCTs $(n=1067)$ [19-23], 6 cohort studies ( $n=881$ ) [24-29], and 16 case series $(n=35,508)$ were included for the qualitative analysis. Then, 5 RCTs and the 6 cohort studies were included in the quantitative analysis (Supplementary Figure S1). Among RCTs, Avendaño-Solà et al. [21] and Agarwal et al. [22] included only moderate COVID-19 patients, while Li et al. [19], Gharbharan et al. [20], and Simonovich et al. [23] included patients with severe COVID-19. All RCTs and cohorts evaluated CP vs. SOC, except Simonovich et al. [23], where the control group was placebo + SOC.

Table I shows baseline characteristics of eleven studies, 5 RCTs and 6 cohorts, evaluating COVID-19 patients from Argentina, China, India, Iran, Iraq, Netherlands, Spain and the United States [19-29]. Avendaño-Solà et al.[21] included patients with $\mathrm{SpO}_{2}$ $\leq 94 \%$ but excluded those in mechanical ventilation or high-flow oxygen devices. Sample size ranged widely from 21 to 387 patients. Median age ranged between 47.8 and 73.0 , severity was defined as respiratory distress, respiratory rate $>30$, hypoxemia with $\mathrm{SpO}_{2}<93 \%, \mathrm{PaFiO}_{2}<300$, pulmonary infiltrates $>50 \%$, or life-threatening disease (mechanical ventilation, septic shock, multi-organ dysfunction). Across studies, mean prevalence rates of comorbidities were: hypertension $40 \%$, obesity $34.9 \%$, diabetes $30.3 \%$, and CAD 19.2\%.

There was heterogeneity of the timing of CP administration from symptom appearance or COVID-19 diagnosis to randomization, ranging from 8 days [21, 23] to 41 days [22] (Supplementary Table SI). Antibody titers of donors were also heterogeneous, ranging from at least $>1: 20$ [22] to at least $>1: 640$ [19]. Also, the percentage of positivity of antibodies in patients at randomization ranged from $0 \%$ [19] to $83 \%$ [22].

Outcomes such as all-cause mortality, clinicalimprovement, and serious and overall adverse events are shown in Supplementary Table SII. All-cause mortality was the common outcome in every study, clinical improvement was only reported in 3 RCTs and 2 cohorts, clinical worsening or progression in 2 RCTs, and need for invasive ventilation in 2 RCTs. Adverse events were found in 3 RCTs and 3 cohorts, and SAEs in 3 RCTs. Details of included RCTs and cohorts are described in the supplementary material (Supplementary Appendix S2).

Our study also included 16 case series [12, S1S15] with 35508 patients from all over the world. Most patients were male and over 51 years old. Dosing and frequency were very heterogeneous, ranging from $200 \mathrm{ml}$ to $500 \mathrm{ml}$, with $200 \mathrm{ml}$ being the most used dosage. Almost all patients received 1 dose; however, some of them were scheduled to receive 2 or even 3 doses. The most repeated primary outcomes were mortality and clinical improvement. Other studies evaluated clinical scores such as SOFA and $\mathrm{PaFiO}_{2}$ as well as adverse events.

Quality of evidence was low or very low for most of clinical and composite safety outcomes (Table II and Supplementary Table SIII). Gharbharan et al. [20] and Simonovich et al. RCTs [23] showed some concerns of bias in the randomization process, the $\mathrm{Li}$ et al. [16] RCT showed some concerns of bias in the randomization process and in deviation from intend- 


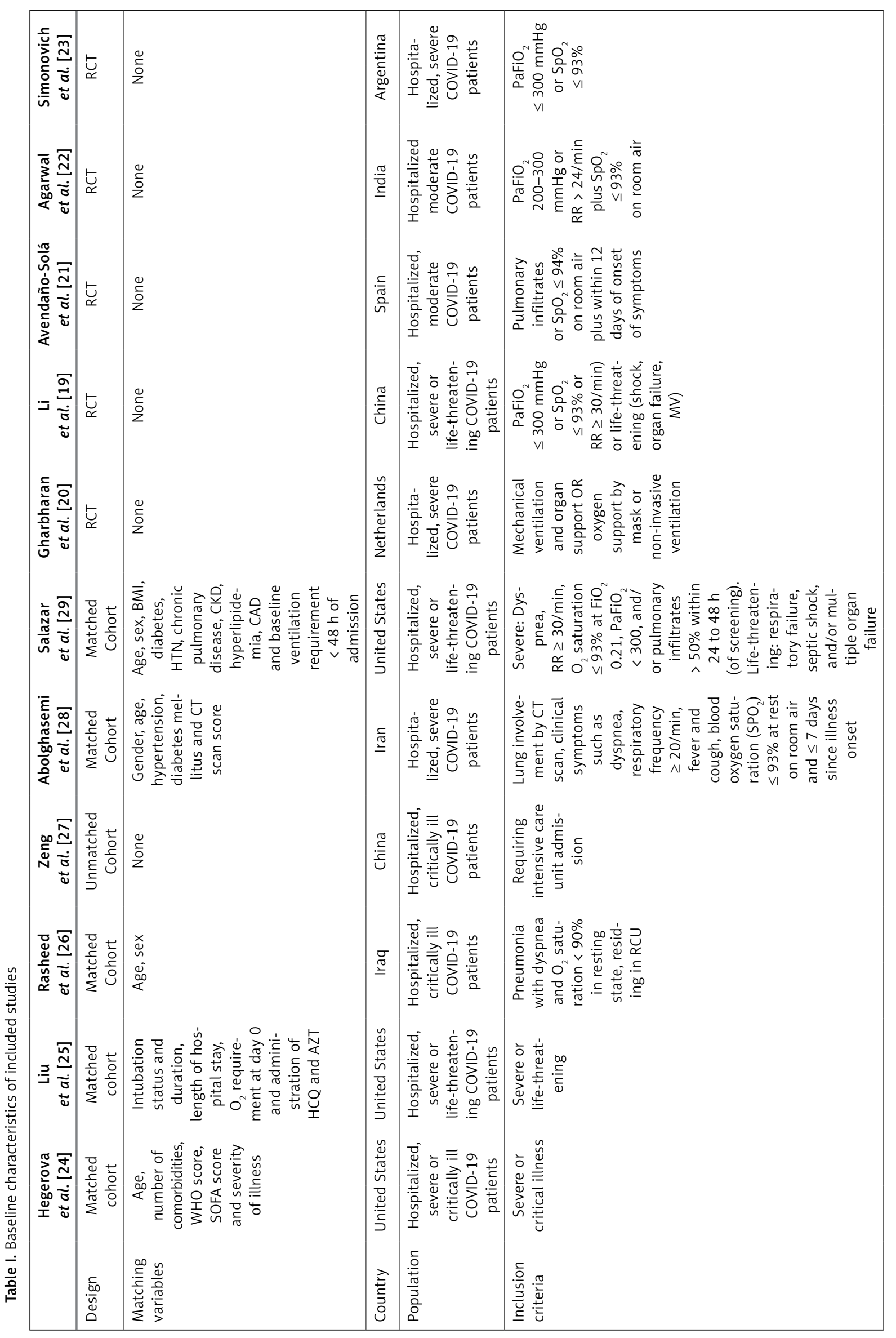




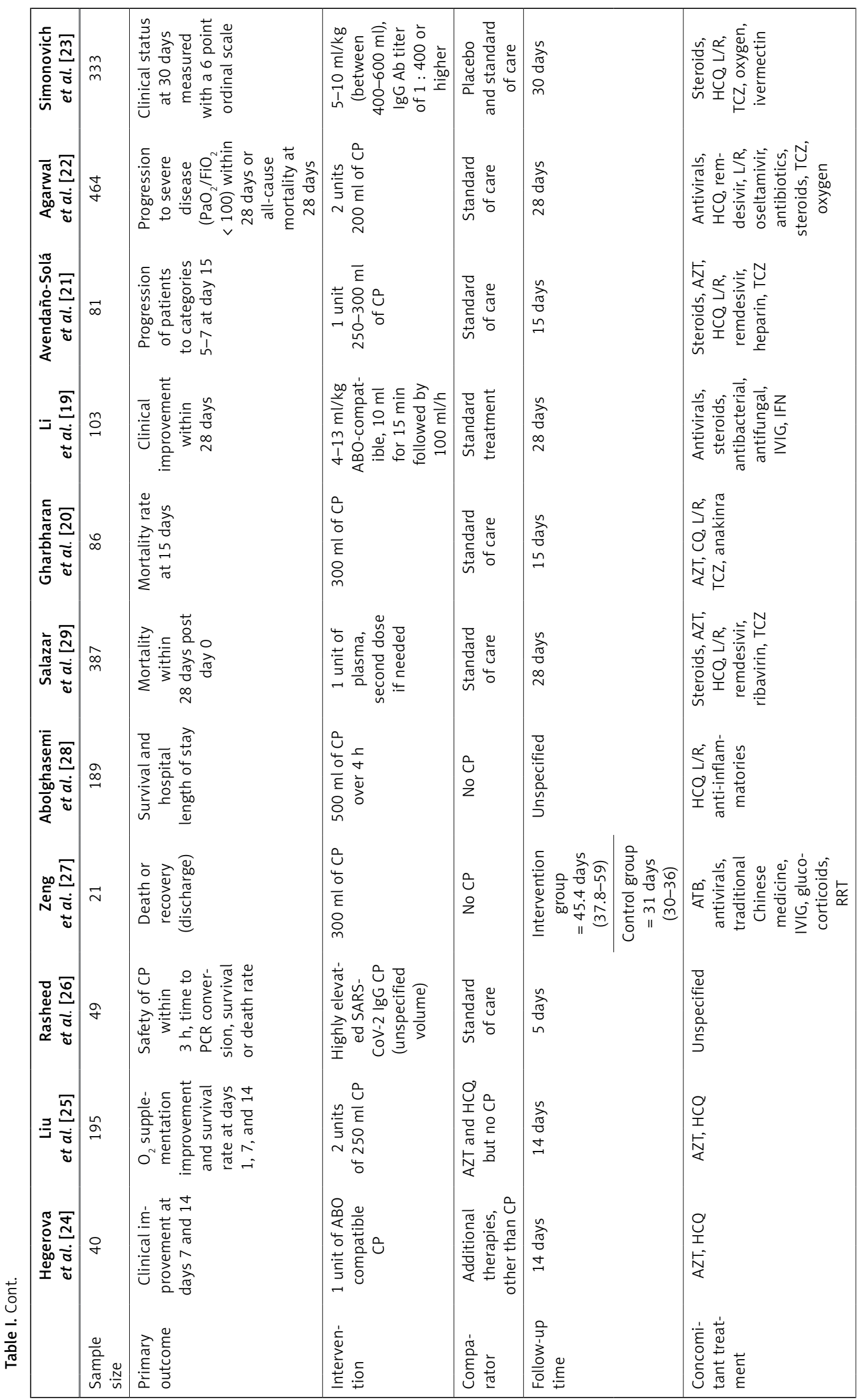




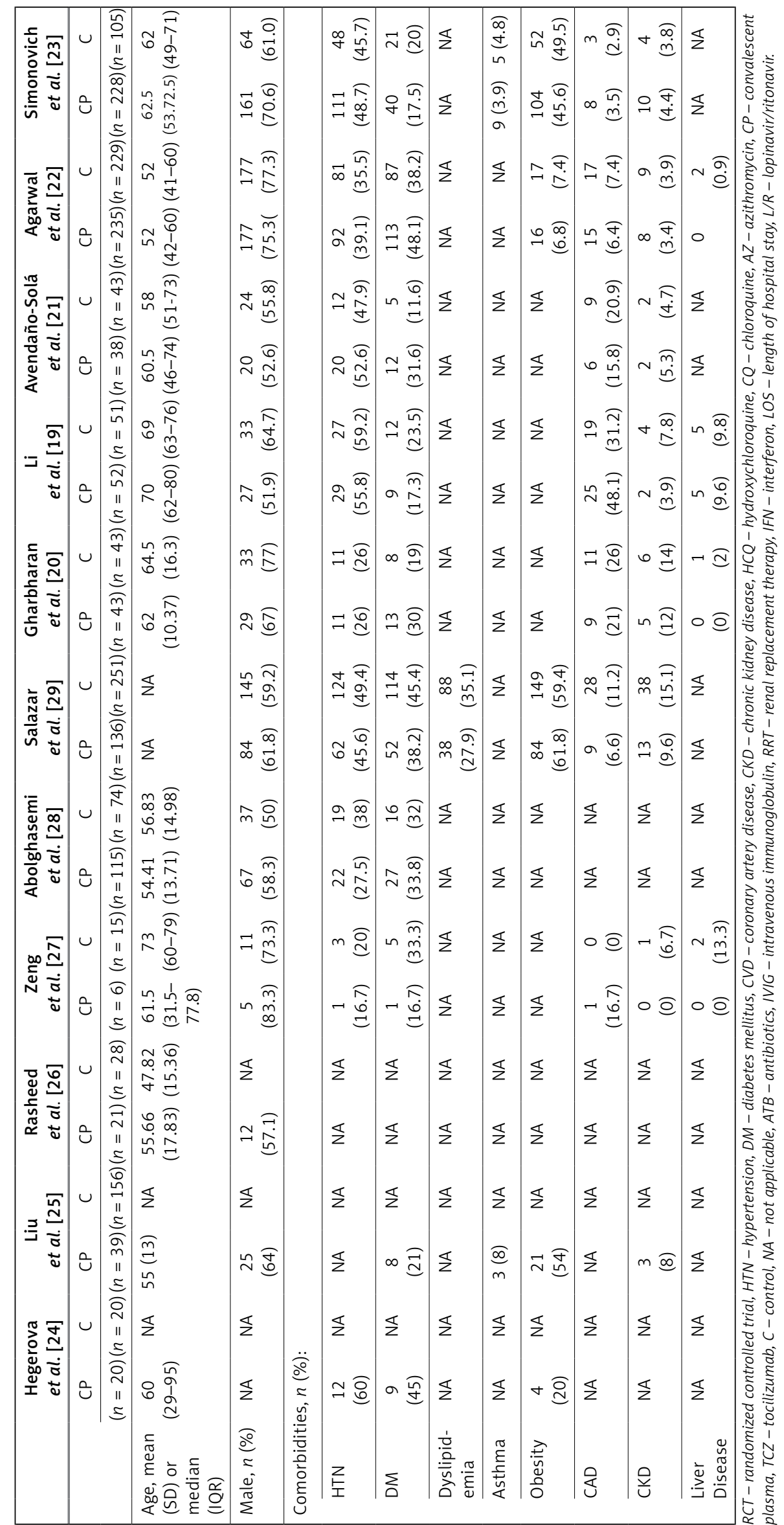


Table II. Summary of findings table of convalescent plasma compared to standard of care in hospitalized COVID-19 patients

\begin{tabular}{|c|c|c|c|c|c|}
\hline \multirow[t]{2}{*}{ Outcomes } & \multicolumn{2}{|c|}{$\begin{array}{l}\text { Anticipated absolute ef- } \\
\text { fects* }^{*}(95 \% \mathrm{Cl})\end{array}$} & \multirow[t]{2}{*}{$\begin{array}{l}\text { Relative effect } \\
\quad(95 \% \mathrm{Cl})\end{array}$} & \multirow[t]{2}{*}{$\begin{array}{l}\text { No of partici- } \\
\text { pants (studies) }\end{array}$} & \multirow{2}{*}{$\begin{array}{l}\text { Certainty of } \\
\text { the evidence } \\
\text { (GRADE) }\end{array}$} \\
\hline & $\begin{array}{l}\text { Risk with } \\
\text { standard } \\
\text { of care }\end{array}$ & $\begin{array}{l}\text { Risk with } \\
\text { convalescent } \\
\text { plasma }\end{array}$ & & & \\
\hline $\begin{array}{l}\text { All-cause mortality in severe patients } \\
\text { follow-up: range } 15 \text { days to } 28 \text { days }\end{array}$ & 24 per 100 & $\begin{array}{l}15 \text { per } 100 \\
(8 \text { to } 27)\end{array}$ & $\begin{array}{c}\text { RR } 0.60 \\
\text { (0.33 to } 1.10)\end{array}$ & $\begin{array}{c}189 \\
\text { (2 RCTs) }\end{array}$ & $\underset{L^{\prime} W^{\mathrm{a}, \mathrm{b}}}{\oplus}$ \\
\hline $\begin{array}{l}\text { All-cause mortality in moderate } \\
\text { patients follow-up: range } 15 \text { days to } \\
28 \text { days }\end{array}$ & 13 per 100 & $\begin{array}{l}8 \text { per } 100 \\
(1 \text { to } 50)\end{array}$ & $\begin{array}{c}\text { RR } 0.60 \\
\text { (0.09 to } 3.86)\end{array}$ & $\begin{array}{c}545 \\
(2 \text { RCTs) }\end{array}$ & $\begin{array}{l}\oplus \bigcirc \bigcirc \bigcirc \\
\text { VERY LOW }\end{array}$ \\
\hline $\begin{array}{l}\text { All-cause mortality in severe patients } \\
\text { follow-up: range } 5 \text { days to } 45 \text { days }\end{array}$ & 19 per 100 & $\begin{array}{l}12 \text { per } 100 \\
(9 \text { to } 17)\end{array}$ & $\begin{array}{c}\text { RR } 0.66 \\
(0.49 \text { to } 0.91)\end{array}$ & $\begin{array}{c}881 \\
\text { (6 observational } \\
\text { studies) }\end{array}$ & $\begin{array}{l}\oplus \bigcirc \bigcirc \bigcirc \\
\text { VERY LOWfg }\end{array}$ \\
\hline $\begin{array}{l}\text { Clinical improvement in severe patients } \\
\text { assessed with: patient discharged alive } \\
\text { or improvement of } 2 \text { categories on a } \\
\text { 6-point severity scale (from } 1 \text { (discharge) } \\
\text { to } 6 \text { (death)) follow-up: mean } 28 \text { days }\end{array}$ & 43 per 100 & $\begin{array}{l}55 \text { per } 100 \\
(36 \text { to } 75)\end{array}$ & $\begin{array}{c}\text { HR } 1.40 \\
\text { (0.79 to } 2.49)\end{array}$ & $\begin{array}{c}103 \\
(1 \mathrm{RCT})\end{array}$ & $\underset{\mathrm{LOW}}{\oplus \oplus \bigcirc \mathrm{O}, \mathrm{i}}$ \\
\hline $\begin{array}{l}\text { Improvement in severe patients } \\
\text { assessed with: undefined using } \\
\text { adjusted proportional odds models of } \\
\text { WHO 8-point ordinal scale } \\
\text { follow-up: mean } 15 \text { days }\end{array}$ & 14 per 100 & $\begin{array}{l}17 \text { per } 100 \\
(8 \text { to } 35)\end{array}$ & $\begin{array}{c}\text { OR } 1.30 \\
(0.52 \text { to } 3.32)\end{array}$ & $\begin{array}{c}86 \\
(1 \mathrm{RCT})\end{array}$ & $\begin{array}{l}\oplus \bigcirc \bigcirc \bigcirc \\
\text { VERY LOW',k, }\end{array}$ \\
\hline $\begin{array}{l}\text { Clinical worsening in moderate } \\
\text { patients assessed with: progression to } \\
\text { categories } 5,6 \text {, } \\
\text { and } 7 \text { on a } 7 \text {-point ordinal scale (from } \\
1 \text { (discharge) to } 7 \text { (death)) } \\
\text { follow-up: mean } 15 \text { days }\end{array}$ & 14 per 100 & $\begin{array}{l}0 \text { per } 100 \\
(0 \text { to } 0)\end{array}$ & not estimable & $\begin{array}{c}81 \\
(1 \mathrm{RCT})\end{array}$ & $\begin{array}{l}\oplus \bigcirc \bigcirc \bigcirc \\
\text { VERY LOW }\end{array}$ \\
\hline $\begin{array}{l}\text { Progression to severe disease in } \\
\text { moderate patients assessed with: } \\
\mathrm{PaO}_{2} / \mathrm{FiO}_{2}<100 \text { any time within } \\
28 \text { days follow-up: mean } 28 \text { days }\end{array}$ & 7 per 100 & $\begin{array}{l}7 \text { per } 100 \\
(4 \text { to } 14)\end{array}$ & $\begin{array}{c}\text { RR } 0.97 \\
\text { (0.51 to } 1.86)\end{array}$ & $\begin{array}{c}464 \\
(1 \mathrm{RCT})\end{array}$ & $\begin{array}{l}\oplus \oplus \oplus \bigcirc \\
\text { MODERATEn }\end{array}$ \\
\hline $\begin{array}{l}\text { Need of invasive ventilation in moderate } \\
\text { patients follow-up: mean } 28 \text { days }\end{array}$ & 8 per 100 & $\begin{array}{l}7 \text { per } 100 \\
(4 \text { to } 12)\end{array}$ & $\begin{array}{c}\text { RR } 0.85 \\
(0.47 \text { to } 1.55) \\
\end{array}$ & $\begin{array}{c}545 \\
(2 \mathrm{RCTs}) \\
\end{array}$ & $\begin{array}{l}\oplus \bigcirc \bigcirc \bigcirc \\
\text { VERY LOWc,o }\end{array}$ \\
\hline $\begin{array}{l}\text { Adverse events in severe patients } \\
\text { follow-up: mean } 28 \text { days }\end{array}$ & 0 per 100 & $\begin{array}{l}0 \text { per } 100 \\
(0 \text { to } 0)\end{array}$ & not estimable & $\begin{array}{c}103 \\
(1 \mathrm{RCT})\end{array}$ & $\begin{array}{l}\oplus \bigcirc \bigcirc \bigcirc \\
\text { VERY LOWh,p }\end{array}$ \\
\hline $\begin{array}{l}\text { Adverse events in moderate patients } \\
\text { follow-up: mean } 28 \text { days }\end{array}$ & 3 per 100 & $\begin{array}{l}3 \text { per } 100 \\
(1 \text { to } 8)\end{array}$ & $\begin{array}{c}\text { RR } 0.97 \\
\text { (0.32 to } 2.98)\end{array}$ & $\begin{array}{c}464 \\
(1 \mathrm{RCT})\end{array}$ & $\begin{array}{l}\oplus \oplus \oplus \bigcirc \\
\text { MODERATE }\end{array}$ \\
\hline $\begin{array}{l}\text { Severe adverse events in severe } \\
\text { patients assessed with: pulmonary } \\
\text { edema, severe allergic reaction, } \\
\text { anaphylactic shock follow-up: mean } \\
28 \text { days }\end{array}$ & 0 per 100 & $\begin{array}{l}0 \text { per } 100 \\
(0 \text { to } 0)\end{array}$ & $\begin{array}{c}\text { RR } 1.92 \\
\text { (0.16 to } 22.69)\end{array}$ & $\begin{array}{c}189 \\
(2 \mathrm{RCTs})\end{array}$ & $\begin{array}{l}\oplus \bigcirc \bigcirc \bigcirc \\
\text { VERY LOWa,r }\end{array}$ \\
\hline $\begin{array}{l}\text { Severe adverse events in moderate pa- } \\
\text { tients assessed with: pulmonary edema, } \\
\text { severe allergic reaction, anaphylactic } \\
\text { shock follow-up: mean } 15 \text { days }\end{array}$ & 16 per 100 & $\begin{array}{l}16 \text { per } 100 \\
(6 \text { to } 43)\end{array}$ & $\begin{array}{c}\text { RR } 0.97 \\
\text { (0.36 to } 2.64)\end{array}$ & $\begin{array}{c}81 \\
(1 \mathrm{RCT})\end{array}$ & $\begin{array}{l}\oplus \bigcirc \bigcirc \bigcirc \\
\text { VERY LOW', }\end{array}$ \\
\hline
\end{tabular}

${ }^{a}$ RoB 2.0: Gharbharan et al. RCT had some concerns of risk of bias in the randomization process; Li et al. had some concerns of risk of bias in the randomization process and in deviation from the intended interventions. ${ }^{b}$ Imprecision: $95 \% \mathrm{Cl}$ of the effect was 0.09 to 13.86 . 'ROB 2.0: Avendaño-Solà et al. RCT had high risk of bias in the randomization process; Agarwal et al. RCT had low risk of bias. dinconsistency: $I^{2}=51 \%$. ${ }^{e}$ Imprecision: $95 \% \mathrm{Cl}$ of the effect was 0.01 to 2.26 . ${ }^{f}$ RoB ROBINS-I: All 6 cohorts had serious risk of bias due to residual confounding and selection of participants for the study. ${ }^{9}$ mprecision: $95 \% \mathrm{Cl}$ of the effect was 0.49 to $0.91 .{ }^{h} \mathrm{RoB} 2.0: \mathrm{Li}$ et al. had some concerns of risk of bias in the randomization process and in deviation from the intended interventions. ${ }^{1} / \mathrm{mprecision}$ : $95 \% \mathrm{Cl}$ of the effect was 0.79 to 2.49. ${ }^{j} R O B$ 2.0: Gharbharan et al. RCT had some concerns of risk of bias in the randomization process. ${ }^{k}$ Indirectness: Improvement of the WHO 8-point ordinal scale was not defined in manuscript or supplement of Gharbharan et al. RCT. 1/mprecision: 95\% Cl of the effect was 0.52 to $3.22 .{ }^{\mathrm{m}} /$ mprecision: $95 \% \mathrm{Cl}$ of the relative effect was 0 to infinite. $R D$ was $-14 \%(95 \% \mathrm{Cl}:-24.3 \%$ to $-3.6 \%)$. "Imprecision: $95 \% \mathrm{Cl}$ of the effect was 0.51 to $1.86 .{ }^{\circ}$ Imprecision: $95 \% \mathrm{Cl}$ of the effect was 0.47 to $1.55 .{ }^{p}$ Imprecision: $95 \% \mathrm{Cl}$ of the relative effect was undefined. $R D$ was $3.8 \%$ (95\% Cl: $-1.4 \%$ to $9.1 \%$ ). ${ }^{9}$ Imprecision: $95 \% \mathrm{Cl}$ of the effect was 0.32 to 2.98 . $1 / \mathrm{mprecision}$ : $95 \% \mathrm{Cl}$ of the relative effect was 0.16 to $22.69 .5 /$ mprecision: $95 \% \mathrm{Cl}$ of the effect was 0.36 to 2.64 . 
ed interventions, the Avendaño-Solà et al. [18] RCT showed high risk of bias in the randomization process, and Agarwal et al. [19] reported low risk of bias (Supplementary Figure S2). The 6 cohort studies showed serious risk of bias due to potential confounding, and selection of participants for the study; 2 cohorts had serious risk of bias in classification of interventions and 3 cohorts had serious risk of bias in selection of the reporting results (Supplementary Figure S3).

Convalescent plasma had no effect on the risk of all-cause mortality vs. SOC in 2 RCTs $[16,17]$ of severe COVID-19 patients ( $R R=0.60,95 \% \mathrm{Cl}$ : 0.33-1.10) (Figure 1). Convalescent plasma did not have an effect on all-cause mortality vs. SOC in 2 RCTs $[18,19]$ of moderate COVID-19 patients $(\mathrm{RR}=0.60,95 \% \mathrm{Cl}: 0.09-3.86)$ (Figure 2). Among cohort studies at serious risk of bias [20-25], the reduction of all-cause mortality was significant vs. SOC (RR $=0.66,95 \% \mathrm{Cl}: 0.49-0.91)$ (Figure 3). Clinical improvement or improvement was scarcely and heterogeneously reported for the comparison of CP vs. SOC. Convalescent plasma did not have an effect on the need for invasive ventilation vs. SOC in 2 RCTs $[18,19]$ of moderate COVID-19 patients ( $R R=0.85,95 \% \mathrm{Cl}$ : 0.47-1.55) (Supplementary Figure S4). Adverse events and SAEs were very scarce and similar between $\mathrm{CP}$ and SOC; SAES between CP and SOC were similar in 2 RCTs [16, 17] of severe COVID-19 patients ( $R R=1.92$, $95 \%$ $\mathrm{Cl}$ : 0.16-22.69). There was not enough information about secondary outcomes to perform a meta-analysis.

Convalescent plasma had no effect on the risk of all-cause mortality vs. control (placebo plus SOC) in 3 RCTs $[19,20,23]$ of severe COVID-19 patients ( $R R=0.75,95 \% \mathrm{Cl}: 0.48-1.16)$ (Supplementary Figure S5). Clinical improvement was not different between $C P$ and control (placebo plus SOC) in 2 RCTs $[19,23]$ of severe COVID-19 patients (HR $=1.07,95 \% \mathrm{Cl}: 0.82-1.40)$ (Supplementary Figure S6). In comparison to the control (placebo plus SOC), CP had no effect on adverse

\begin{tabular}{|c|c|c|c|c|c|c|c|c|c|}
\hline \multirow[t]{2}{*}{ Study } & \multicolumn{2}{|c|}{ Experimental } & \multicolumn{2}{|c|}{ Control } & \multirow[t]{2}{*}{ Risk ratio } & \multirow[t]{2}{*}{$\mathrm{RR}$} & \multirow[t]{2}{*}{$95 \% \mathrm{Cl}$} & \multirow{2}{*}{$\begin{array}{l}\text { Weight } \\
\text { (fixed) }\end{array}$} & \multirow{2}{*}{$\begin{array}{l}\text { Weight } \\
\text { (random) }\end{array}$} \\
\hline & Events & Total & Events & Total & & & & & \\
\hline Gharbaran et al. 2020 & 6 & 43 & 11 & 43 & & 0.55 & {$[0.22 ; 1.34]$} & $44.5 \%$ & $44.5 \%$ \\
\hline Li et al. 2020 & 8 & 52 & 12 & 51 & + & 0.65 & {$[0.29 ; 1.47]$} & $55.5 \%$ & $55.5 \%$ \\
\hline Fixed effect model & & 95 & & 94 & & 0.60 & {$[0.33 ; 1.10]$} & $100.0 \%$ & - \\
\hline \multicolumn{5}{|c|}{ Random effects model } & - & 0.60 & {$[0.33 ; 1.10]$} & - & $100.0 \%$ \\
\hline \multicolumn{5}{|c|}{ Heterogeneity: $l^{2}=0 \%, \tau^{2}=0, p=0.77$} & & & & & \\
\hline
\end{tabular}

Figure 1. Effect of convalescent plasma on all-cause mortality in RCTs of severe COVID-19 patients

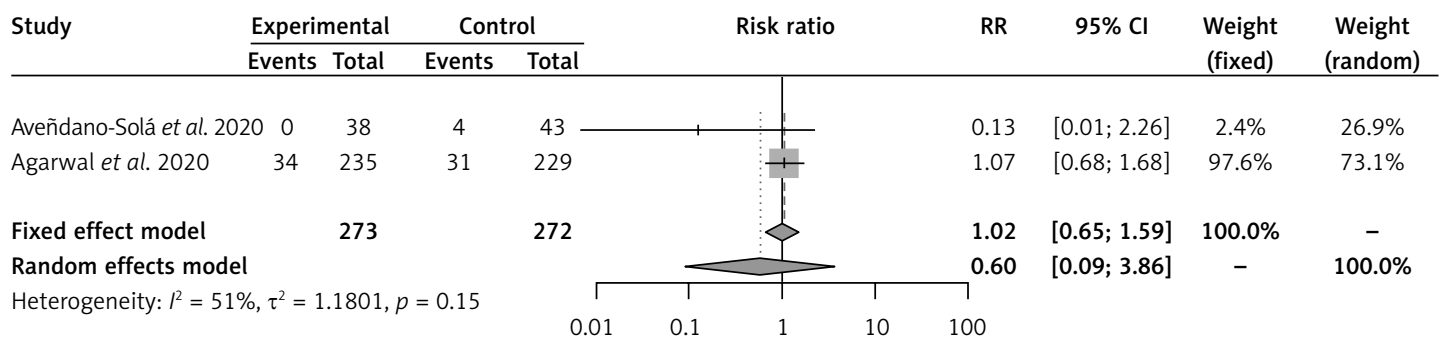

Figure 2. Effect of convalescent plasma on all-cause mortality in RCTs of moderate COVID-19 patients

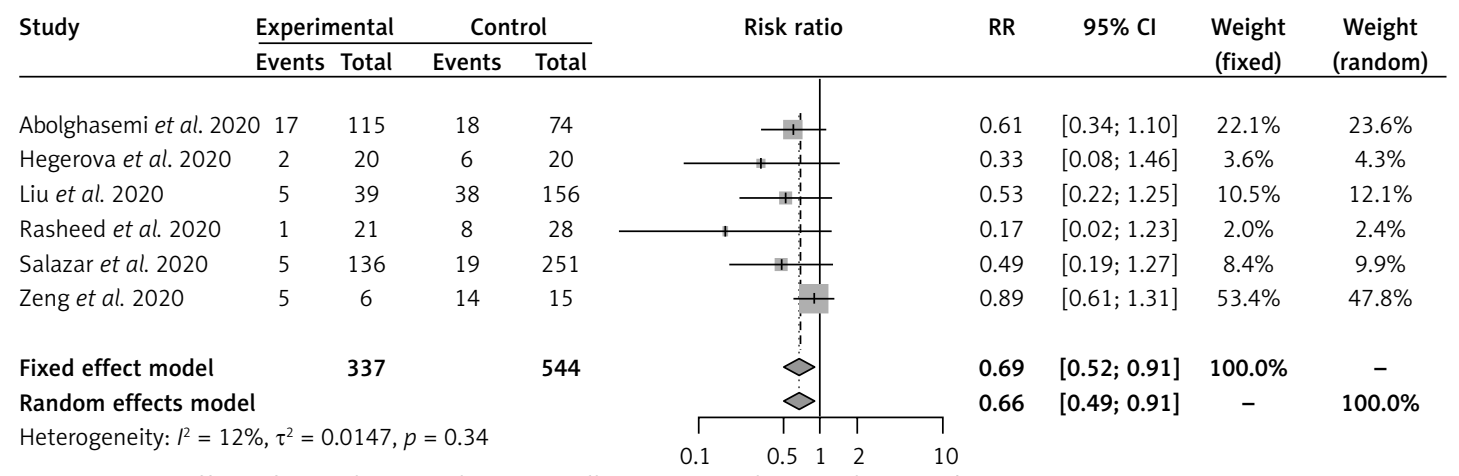

Figure 3. Effect of convalescent plasma on all-cause mortality in cohort studies in severe COVID-19 patients 
events $(R R=1.07,95 \% \mathrm{Cl}: 0.90-1.28)[19,23]$ or SAEs (RR $=1.33,95 \% \mathrm{Cl}: 0.84-2.10)[19,20,23]$ in severe COVID-19 patients (Supplementary Figures $\mathrm{S} 7$ and S8). Although subgroup findings were restricted by the limited number of outcomes and RCTs, there were no differences of CP effects across RCTs by severity of disease, by type of control, or by other differences across RCTs (timing of $\mathrm{CP}$ administration, by titers of antibodies in donors, and by percentage of positivity of antibodies to SARS-CoV-2 at randomization) (all $p$ for interaction $>0.2$ ).

We identified 56 ongoing RCTs taking place worldwide; 36 studies compare CP to standard treatment of care while the other 20 use a placebo such as standard plasma, albumin, immunoglobulin, saline or Ringer's lactate as the comparator. Almost all of them include serious or critically ill patients. Supplementary Table SIV describes their details.

\section{Discussion}

Convalescent plasma did not show an all-cause mortality benefit compared to placebo or standard of care in RCTs of severe and moderate hospitalized COVID-19 patients. However, we found a significant all-cause mortality benefit among 6 cohorts at serious risk of bias, 5 of them with some degree of matching for potential confounders. There was a scarcity of outcome data about clinical improvement or worsening, need of invasive ventilation, or length of stay across studies. Most of the studies reported scarce or no adverse events or serious adverse events, and there were no differences between $C P$ and standard of care or placebo plus standard of care arms. Three out of 5 RCTs were stopped prematurely due to the lack of new patients or the presence of neutralizing antibodies at baseline. Quality of evidence was low or very low for most clinical and composite safety outcomes.

There are previously published reviews [30-34] of the efficacy and harms of the use of CP in severely ill patients with COVID-19: 2 narrative reviews $[30,34]$, and 3 systematic reviews (SR) [31-33]. However, none of these reviews evaluated all the studies we included and only Joyner et al. [30] included a meta-analysis. Joyner et al. [30] evaluated 3 RCTs, 5 matched-control studies, and 4 case series and concluded that mortality was diminished in the CP group among the RCTs $(O R=0.46)$ and among the matched-control studies $(O R=$ 0.41). Nevertheless, the authors did not report $95 \% \mathrm{Cl}$, mistakenly used OR and a fixed effects model for the meta-analysis, and misclassified the Rasheed et al. study [26] as an RCT when it is a matched-control cohort study.

Valk et al. [32] performed an SR that included only 1 RCT and 3 controlled non-randomized studies of interventions (NRSI) in the quantitative analysis. They reported uncertainty for the effect of CP on all-cause mortality $(R R=0.89$, $95 \% \mathrm{Cl}: 0.61-1.31)$, on clinical improvement at 7 days ( $R R=0.98,95 \% \mathrm{Cl}: 0.30-3.19)$, at 14 days $(\mathrm{RR}=1.85,95 \% \mathrm{Cl}: 0.91-3.77)$, and at 28 days (RR $=1.20,95 \% \mathrm{Cl}: 0.80-1.81)$. They did not perform a meta-analysis due to critical risk of bias in the controlled NRSIs. Valk et al. [32] performed a narrative review that included 8 case series, 1 singlearm intervention study, and no RCTs. Results of this study showed inconsistent data due to their high risk of bias and a low reporting quality. All their studied patients were alive at the end of the reporting period but not all had been discharged.

Rajendran et al. [33] was an SR that included 5 studies (1 pilot study, 1 preliminary communication, 1 novel report, 1 report case and 1 descriptive study) from China and South Korea. The heterogeneity of designs did not allow them to perform a meta-analysis. These authors reported that CP use in variable doses may have a beneficial effect on mortality rate among COVID-19 patients, but they stated that findings of zero mortality in those studies could also be due to a synergistic effect of the multiple other agents received by those patients. They also reported that CP may cause an improvement in clinical status, and with very minimal or no adverse events.

Finally, a pre-print of an SR by Pimenoff et al. [34] included ten studies with only 61 patients and neither specification of each type of study nor a PRISMA figure. There were no significant differences in time to clinical improvement between genders, between those with or without comorbidities and between those receiving CP within the first week of symptoms or after 3 weeks of symptoms onset. The authors did not analyze mortality or adverse events.

There were 2 previous SRs which evaluated CP in non-COVID-19 patients. Sun et al. [35] evaluated 40 studies of CP in infectious diseases such as SARS, MERS, pandemic influenza and Ebola, finding a significantly lower mortality rate in the intervention group ( $\mathrm{OR}=0.32,95 \% \mathrm{Cl}: 0.19-0.52)$. Devasenapathy et al. [36] pooled 4 RCTs on influenza patients and reported no effect of CP on mortality $(\mathrm{RR}=0.94,95 \% \mathrm{Cl}: 0.49-1.81)$, clinical improvement $(\mathrm{OR}=1.04,95 \% \mathrm{Cl}: 0.69-1.64)$, and length of hospital stay (MD $=-1.62,95 \% \mathrm{Cl}:-3.82$ to -0.58). Furthermore, they did not find an association between CP and serious adverse events $(\mathrm{RR}=0.85,95 \% \mathrm{Cl}:$ 0.56-1.29).

Although it is reasonable to think that early administration of CP may improve mortality in COVID-19, this has been found in a case series study by Cheng et al. [8] comparing < 14 days vs. > 14 days of COVID-19 (mortality rates: $6.3 \%$ 
vs. $21.9 \%$, respectively). Also, the FDA emergency use authorization of CP was based on subgroup analyses by time of administration (7-day mortality rate was $8.7 \%(95 \% \mathrm{Cl}: 8.3-9.2 \%)$ in patients transfused within 3 days of COVID-19 diagnosis but $11.9 \%(11.4-12.2 \%)$ in patients transfused 4 or more days after diagnosis $(p<0.001)$ ), and subgroup analyses by IgG concentration of CP (7-day mortality rate was $8.9 \%$ with high IgG levels vs. $13.7 \%$ with low IgG levels) in another large case series by Joyner et al. [12]. Case series studies are exploratory and cannot provide estimates of efficacy or effectiveness as there is no control group; findings in case series studies may be due to the effect of confounders or other differences in the groups being compared.

The Agarwal et al. RCT [22] was different from other RCTs. In this study, the median time from COVID-19 diagnosis to intervention was 41 days, which is longer than the 8 to 30 day range from COVID-19 symptoms to randomization of the other 4 RCTs [19-21, 23]. In addition, Agarwal et al. reported that $83 \%$ of the intervention and control individuals had positive total neutralizing SARSCoV-2 antibodies at randomization, and that only $64 \%$ of donors reached antibodies titers of at least 1 : 20 (median titer of $1: 40$ ). These findings differed from the other 4 RCTs, where the percentage positivity of neutralizing SARS-CoV-2 antibodies ranged between 0\% [19] and 80\% [20], and the antibody titers of donors ranged between at least $1: 80[20,21]$ and at least $1: 640[19]$. How ever, there were no differences of $C P$ effects across these RCTs.

Our study has several strengths. First, we performed a systematic review and an extensive search in 5 engines, 1 pre-print website, and 3 clinical trial registries. Second, our study provides the most up-to-date and recent data until November 24, 2020 compared to the other SRs. Third, we have assessed risk of bias for RCTs and cohorts using the latest tools by Cochrane, RoB 2.0. and ROBINS-I, respectively. Fourth, we also evaluated the quality or certainty of evidence per outcome among all evaluated controlled studies using GRADE methodology. Fifth, in addition to the SR, we could meta-analyze all-cause mortality in 2 similar RCTs of severe and 2 RCTs of moderate COVID-19 patients; cohorts were meta-analyzed independently. Sixth, we formally evaluated adverse event reporting and test differences between $\mathrm{CP}$ and controls groups. Finally, we ran an extensive search of the ongoing parallel RCTs evaluating efficacy and safety of CP in COVID-19 patients worldwide.

In conclusion, in PCR-confirmed, COVID-19 hospitalized adult patients, there is a lack of fully powered and adequately reported RCTs evaluating the efficacy and safety of CP. One RCT was stopped early due to lack of new patients in Wuhan, China, a second RCT was stopped prematurely due to presence of neutralizing antibodies at baseline, had scarce data about clinical improvement and did not report adverse events, a third RCT evaluated moderately ill patients, had high risk of bias, and was stopped early due to lack of new patients, a fourth RCT assessed moderately ill patients and had low risk of bias, and a fifth RCT evaluated CP vs. placebo plus SOC in severe patients and had some concerns of risk of bias. These trials did not show all-cause mortality benefit with the use of CP vs. SOC or placebo plus SOC in both moderate and severe COVID-19 patients. Although the cohort studies showed a statistically significant effect on all-cause mortality, we identified overall serious risk of bias in all of them. Individual RCTs showed no effect of CP vs. SOC on clinical improvement or worsening or in need of mechanical ventilation, and no effect of CP vs. placebo plus SOC on clinical improvement. There were no differences in adverse events or serious adverse events between $\mathrm{CP}$ and SOC or placebo plus SOC, and these events were scarce across studies.

Overall, the identified studies showed heterogeneous data about timing of administration of CP, antibody titers in donors, and positivity of antibodies at baseline in randomized patients. Controlled studies have shown no effects and low or very low quality of evidence for clinical and adverse effects on these patients, and therefore $C P$ should not be recommended for the treatment of hospitalized COVID-19 patients. Ongoing randomized controlled trials will provide more information on the effects of CP on clinical and safety outcomes in the near future.

\section{Conflict of interest}

The authors declare no conflict of interest.

References

1. World Health Organization (WHO). Coronavirus disease 19 (COVID-19) pandemic. Available at: https://www.who. int/emergencies/diseases/novel-coronavirus-2019 (Accessed: 6.06.2020)

2. Cismaru A, Cismaru L, Nabavi SF, et al. Game of "crowning" season 8: RAS and reproductive hormones in COVID-19 - can we end this viral series? Arch Med Sci 2021; 17: 275-84.

3. Reiner Ž, Hatamipour M, Banach $M$, et al. Statins and the COVID-19 main protease: in silico evidence on direct interaction. Arch Med Sci 2020; 16: 490-6.

4. Worldometer.COVID-19 Coronavirus Pandemic. Available at: https://www.worldometers.info/coronavirus/ (Accessed: 8.05.2020).

5. Liberato N, De Monte A, Caravella G. Tocilizumab in severe COVID-19. Arch Med Sci 2020; 16: 1457-8.

6. Duan K, Liu B, Li C, et al. Effectiveness of convalescent plasma therapy in severe COVID-19 patients. Proc Natl Acad Sci USA 2020; 117: 9490-6. 
7. Ko JH, Seok H, Cho SY, et al. Challenges of convalescent plasma infusion therapy in Middle East respiratory coronavirus infection: a single centre experience. Antivir Ther 2018; 23: 617-22.

8. Cheng Y, Wong R, Soo YOY, et al. Use of convalescent plasma therapy in SARS patients in Hong Kong. Eur J Clin Microbiol Infect Dis 2004; 24: 44-6.

9. Hung IF, To KK, Lee CK, et al. Convalescent plasma treatment reduced mortality in patients with severe pandemic influenza A (H1N1) 2009 virus infection. Clin Infect Dis 2011; 52: 447-56.

10. Dzik S. COVID-19 convalescent plasma: now is the time for better science. Transfus Med Rev 2020; 34: 141-4.

11. U.S Food \& Drug Administration (FDA). FDA Issues Emergency Use Authorization for Convalescent Plasma as Potential Promising COVID-19 Treatment, Another Achievement in Administration's Fight Against Pandemic. 2020. Available at: https://www.fda.gov/news-events/ press-announcements/fda-issues-emergency-use-authorization-convalescent-plasma-potential-promis ing-covid-19-treatment (Accessed: 28.08.2020).

12. Joyner MJ, Senefeld JW, Klassen SA, et al. Effect of convalescent plasma on mortality among hospitalized patients with COVID-19: initial three-month experience. [Pre-print] MedRxiv 2020. DOI: https://doi.org/10.1101 /2020.08.12.20169359.

13. COVID-19 Treatment Guidelines Panel. Coronavirus Disease 2019 (COVID-19) Treatment Guidelines. National Institutes of Health. Available at: https://www.covid19treatmentguidelines.nih.gov (Accessed: 3.08.2020).

14. Sterne JAC, Savović J, Page MJ, et al. RoB 2: a revised tool for assessing risk of bias in randomised trials. BMJ 2019; 366: 14898.

15. Sterne JA, Hernán MA, Reeves BC, et al. ROBINS-I: a tool for assessing risk of bias in non-randomised studies of interventions. BMJ 2016; 355: i4919.

16. Liberati A, Altman DG, Tetzlaff J, et al. The PRISMA statement for reporting systematic reviews and meta-analyses of studies that evaluate healthcare interventions: explanation and elaboration. BMJ 2009; 339: b2700.

17. Balshem $H$, Helfand $M$, Schünemann $H J$, et al. GRADE guidelines: 3. Rating the quality of evidence. J Clin Epidemiol 2011; 64: 401-6.

18. GRADEpro GDT: GRADEpro Guideline Development Tool [Software]. McMaster University, 2020 (developed by Evidence Prime, Inc.). Available from: gradepro.org.

19. Li L, Zhang W, Hu Y, et al. Effect of convalescent plasma therapy on time to clinical improvement in patients with severe and life-threatening COVID-19: a randomized clinical trial. JAMA 2020; 324: 460-70.

20. Gharbharan A, Jordans CCE, Geurtsvankessel C. Convalescent plasma for COVID-19: a randomized clinical trial. [Pre-Print] MedRxiv 2020. DOI: https://doi.org/10.1101/ 2020.07.01.20139857.

21. Avendaño-Solá C, Ramos-Martinez A, Muñez-Rubio E, Ruiz-Antorán B, Malo de Molina R, Torres F. Convalescent plasma for COVID-19: a multicenter, randomized clinical trial. [Pre-Print] MedRxiv 2020. DOI: https://doi. org/10.1101/2020.08.26.20182444.

22. Agarwal A, Mukherjee A, Kumar G, et al. Convalescent plasma in the management of moderate COVID-19 in India: An open-label parallel-arm phase II multicentre randomized controlled trial (PLACID Trial). MedRxiv 2020. DOI: https://doi.org/10.1101/2020.09.03.20187252.

23. Simonovich VA, Burgos Pratx LD, Scibona P, et al. A randomized trial of convalescent plasma in COVID-19 severe pneumonia. N Eng J Med 2021; 384: 619-29.
24. Hegerova L, Gooley T, Sweerus K. Use of convalescent plasma in hospitalized patients with COVID-19 - case series. Blood 2020: 136: 759-62.

25. Liu STH, Lin HM, Baine I. Convalescent plasma treatment of severe COVID-19: a matched control study. [Pre-Print] MedRxiv 2020. DOI: https://doi.org/10.1101/2020. 05.20.20102236

26. Rasheed AM, Fatak DF, Hashim HA. The therapeutic effectiveness of convalescent plasma therapy on treating COVID-19 patients residing in respiratory care units in Baghdad, Iraq. [Pre-Print] MedRxiv 2020. DOI: https:// doi.org/10.1101/2020.06.24.20121905.

27. Zeng QL, Yu ZJ, Gou JJ. Effect of convalescent plasma therapy on viral shedding and survival in patients with coronavirus disease 2019. J Infect Dis 2020; 222: 38-43.

28. Abolghasemi H, Esghi P, Cheraghali AM. Clinical efficacy of convalescent plasma for treatment of COVID-19 infections: Results of a multicenter study. Transfus Apher Sci 2020; 59: 102875.

29. Salazar E, Christensen PA, Graviss EA, et al. Treatment of COVID-19 patients with convalescent plasma reveals a signal of significantly decreased mortality. Am J Pathol 2020; 119: 2290-303.

30. Joyner MJ, Klassen SA, Senefeld JW, Johnson PW, Carter RE. Evidence favouring the efficacy of convalescent plasma for COVID-19 therapy. [Pre-Print] MedRxiv 2020. DOI: https://doi.org/10.1101/2020.07.29.20162917.

31. Piechotta V, Chai KL, Valk SJ. Convalescent plasma or hyperimmune immunoglobulin for people with COVID-19: a living systematic review. Cochrane Database Syst Rev 2020; 7: CD013600.

32. Valk SJ, Piechotta V, Chai KL, et al. Convalescent plasma or hyperimmune immunoglobulin for people with COVID-19: a rapid review. Cochrane Database Syst Rev 2020; 5: CD013600.

33. Rajendran K, Krishnasamy N, Rangarajan J, Rathinam J, Natarajan M, Ramachandran A. Convalescent plasma transfusion for the treatment of COVID-19: systematic review. J Med Virol 2020; 92: 1475-83.

34. Pimenoff $V$, Elfstrom M, Dillner J. A systematic review of convalescent plasma treatment for COVID-19. [PrePrint] MedRxiv 2020; DOI: https://doi.org/10.1101/ 2020.06.05.20122820

35. Sun $\mathrm{M}, \mathrm{Xu} \mathrm{Y}, \mathrm{He} \mathrm{H}$. Potential effective treatment for COVID-19: systematic review and meta-analysis of the severe infectious disease with convalescent plasma therapy. Int J Infect Dis 2020; 98: 334-46.

36. Devasenapathy N, Ye Z, Loeb M, et al. Efficacy and safety of convalescent plasma for severe COVID-19 based on evidence in other severe respiratory viral infections: a systematic review and meta-analysis. CMAJ 2020; 192: E745-55. 